\title{
Kummerowia (Leguminosae, Desmodieae) novedad para la Flora Argentina
}

\author{
RICARDO O. VANNI ${ }^{1}$
}

\begin{abstract}
Resumen: En esta contribución, se menciona por primera vez para la flora argentina la presencia del género Kummerowia Schindl. (Leguminosae, Desmodieae): en la provincia de Misiones fue hallada $K$. striata (Thunb.) Schindl., naturalizada en bordes de ruta y otros ambientes. Se incluye la descripción e ilustración de esta especie, distribución y hábitats, usos y materiales de referencia.
\end{abstract}

Palabras clave: Argentina, Kummerowia, Leguminosae, naturalizada, flora argentina.

Summary: Kummerowia (Leguminosae, Desmodieae), a novelty for the Flora of Argentina. In this paper, it is mentioned for the first time for Argentine flora the presence of the genus Kummerowia Schindl. (Leguminosae, Desmodieae): in the province of Misiones K. striata (Thunb.) Schindl was found naturalized at road edges and other environments. The description and illustration of this species, distribution and habitats, uses and reference materials are included.

Key words: Argentina, Kummerowia, Leguminosae, naturalized, Argentine flora.

\section{INTRODUCCIÓN}

Kummerowia Schindl. es un género con dos especies nativas del este de Asia, introducidas en el norte de América y en Australia (Akiyama \& Ohba, 1985). Por sus características exomorfológicas, es vecino a Desmodium Desv., género bien representado en la Argentina, al que pertenece el "pega-pega", D. incanun DC. Hasta el momento, no se encontraron registros publicados de la introducción en nuestro país de ninguna de las especies de Kummerowia. En esta contribución se menciona por primera vez para la Argentina la presencia de Kummerowia striata (Thunb.) Schindl., coleccionada en la provincia de Misiones.

Es una especie anual, de ciclo primavero-estival y en su área de origen vive, según la bibliografía, en campos abiertos o bordes de ruta. No se sabe con certeza cómo fue introducida en el país, pero pudo haber ingresado alguna semilla junto a las de otra especie forrajera. Desde hace dos años se observa su presencia en Misiones, naturalizada en bordes

${ }^{1}$ Instituto de Botánica del Nordeste, UNNE-CONICET. Fac. Ciencias Agrarias UNNE. gvanni@agr.unne.edu.ar de rutas y otros ambientes, donde aparentemente cumple su ciclo. Muestra una gran agresividad, aumentando su área de distribución año a año.

Kummerowia striata (Thunb.) Schindl. Feddes Repert. Spec. Nov. Regni Veg. 10: 403.1912.

Hedysarum striatum Thunb. Fl. Jap.: 289. 1794. Tipo: Japan, C.P.Thunberg s.n. (SBT 11963, no visto). Fig. 1.

Planta postrada, ramas apoyantes hasta 1 $\mathrm{m}$ long., todas cubiertas con pelos aplicados, blancos. Hojas trifolioladas. Estípulas hasta 6 mm long., unidas en la base del pecíolo, pajizas, longitudinalmente estriadas. Pecíolos 1-1,5 mm long. Folíolos 7-11 x 2-4 mm, elípticos u oblongos, cara inferior con algunos pelos blanquecinos en la vena media, abundantes pelos blancos en el margen, cara superior glabra. Inflorescencias en racimos contraídos, 1-3-floras, en las axilas de las hojas. Flores $6 \mathrm{~mm}$ long., violáceas. Cáliz $2 \mathrm{~mm}$ long. con cinco dientes, ciliados en el margen, bracteado en la base. Estandarte $5 \mathrm{~mm}$ long, más breve que el resto de los pétalos, ovado, uña breve. Alas 5 $\mathrm{mm}$ long, oblongas, muy angostas, uña $2 \mathrm{~mm}$ long. Quilla $6 \mathrm{~mm}$ long., obovada, ancha en el ápice, uña 
Bol. Soc. Argent. Bot. 51 (1) 2016

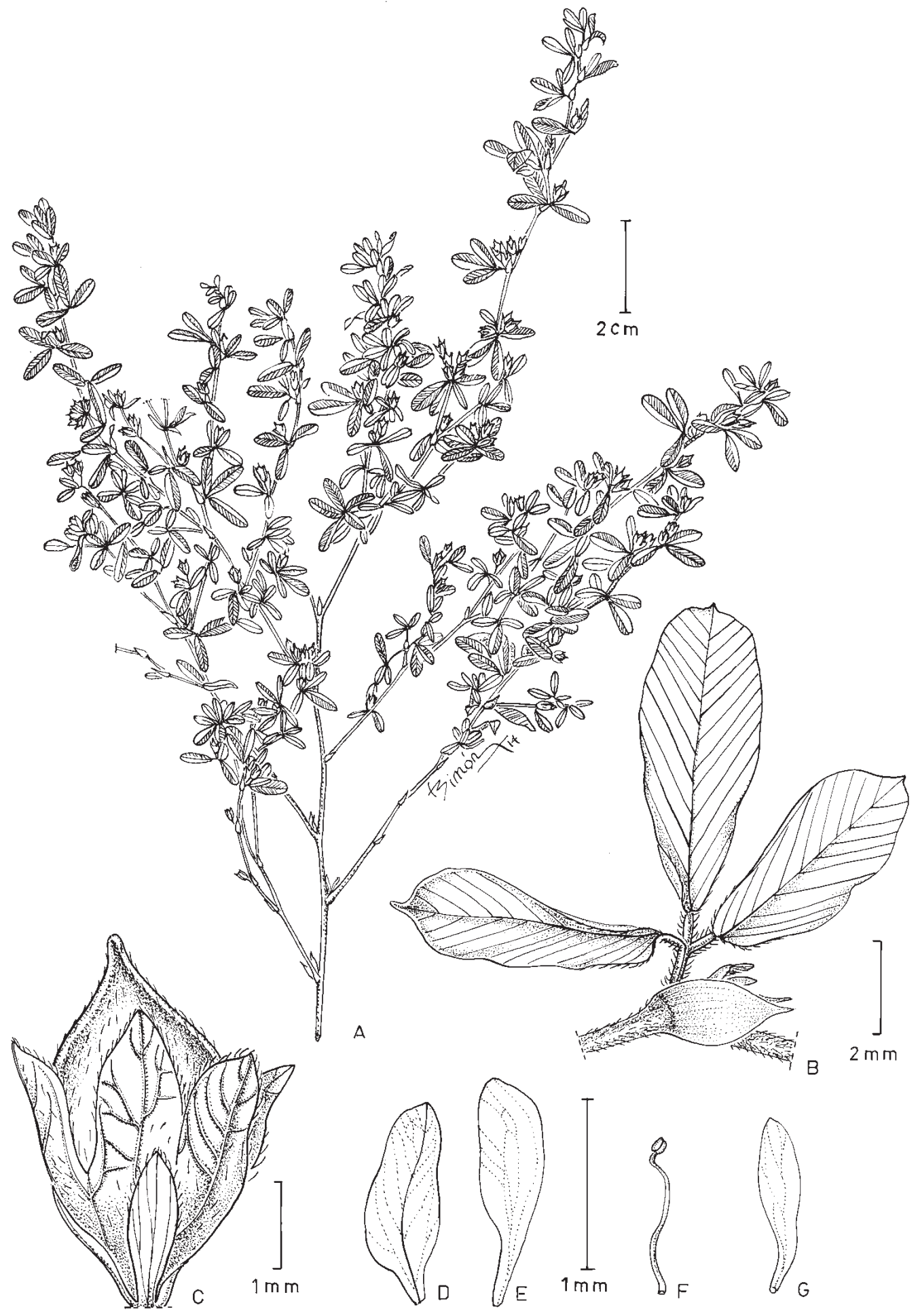

Fig. 1. A: Planta. B: Hoja y estípulas. C: Cáliz acrescente con fruto (Vanni et al. 4662). D: estandarte. E: Quilla. F: Estambre. G: Alas (Keller et al. 9814). 


\section{R. O. Vanni - Kummerowia novedad para la Flora Argentina}

$2 \mathrm{~mm}$ long. Fruto $4 \mathrm{~mm}$ long., ovoide, uniseminado, apiculado, pubérulo, siempre acompañado por el cáliz que es acrescente.

Distribución y hábitats locales. Hasta el momento se limita a la provincia de Misiones, donde fue observada en los departamentos de Eldorado y San Ignacio (H. Keller, comun. verbal). Florece y fructifica de febrero a marzo y se encuentra generalmente en bordes de caminos, asociada con Urochloa brizantha (Hochst. \& A. Rich.) R.D. Webster (Poaceae), "brizanta".

Usos. En los países donde crece se ha utilizado como forrajera, abono verde y medicinal.

Material estudiado: ARGENTINA. Prov. de Misiones. Depto. 25 de Mayo. Borde de ruta, intersección con el Ayo. Acaraguá, 27 30'07,5" S, 54 52'29,4' 'W., 26-II-2011, Keller et al. 9814 (CTES). Idem, 151 m s. m., 31-III-2014, R.Vanni et al. 4662 (CTES, K). Depto. Eldorado. Ciudad de Eldorado, Rta.12, intersección con Avda. El Fundador, 19-IV-2014, Keller 12076 (CTES).

\section{Agradecimientos}

Al Dr. Gwilym Lewis, Royal Botanical Garden, Kew, por haberme indicado de qué especie se trataba el material estudiado. A Laura Simón, por la ilustración.

\section{Bibliografía}

AKIYAMA S. \& H. OHBA. 1985. The branching of the inflorescence and vegetative shoot and taxonomy of the genus Kummerowia (Leguminosae). Bot. Mag. (Tokyo) 98: 137-150.

Recibido el 07 de Julio de 2015, aceptado el 16 de octubre de 2015. 
